\title{
Análise de trilha dos componentes do rendimento de sementes de trevo- branco
}

\author{
Rodrigo Ramos Lopes ${ }^{1}$, Lúcia Brandão Franke ${ }^{2}$ \\ ${ }^{1}$ Programa de Pós-graduação em Zootecnia, Faculdade de Agronomia, Universidade Federal do Rio Grande Sul. Bolsista CNPq. \\ 2 Departamento de Plantas Forrageiras e Agrometeorologia da Faculdade de Agronomia/UFRGS, Caixa Postal 15100, CEP: 91501-970, \\ Porto Alegre, RS.
}

RESUMO - Objetivou-se, por meio de uma análise de trilha para rendimento de sementes em trevo-branco, obter informações básicas para utilização em estratégias de manejo para maior produção de sementes e maior ressemeadura natural, proporcionando assim condições para maior persistência da espécie na pastagem. Foram analisadas as seguintes variáveis: botões florais, número de inflorescências, número de inflorescências maduras, número de legumes/inflorescência, peso de 100 sementes e rendimento de sementes. A variável que mais se correlacionou com o rendimento de sementes foi o número de inflorescências maduras $(r=0,91)$ e essa correlação ocorreu praticamente apenas pelo seu efeito direto. Nas demais variáveis, destacou-se o número de botões florais, com coeficiente de correlação alto $(\mathrm{r}=-0,55)$ e efeitos indiretos sobre os demais componentes. O número de inflorescências maduras parece ser a principal característica a ser considerada na busca de maior produção de sementes em trevo-branco.

Palavras-chave: botão floral, espécie forrageira, número de inflorescências maduras, peso de 100 sementes

\section{Path analysis in white clover seed yield components}

\begin{abstract}
The objective of this study was, by using a path analysis of seed yield in white clover, to obtain basic information for use in management strategies for higher seed production and higher natural reseeding and greater persistence of the species in the pasture. The following variables were analyzed: number of flower buds, number of inflorescences, number of mature inflorescences, number of legumes/inflorescence, weight of 100 seeds and seed yield. The variable most correlated with seed yield was the number of mature inflorescences $(r=0.91)$, and this correlation occurred almost only due to its direct effect. Among the other variables, the number of flower buds also had a high correlation coefficient $(r=0.55)$ and indirect effects on the other components. The number of mature inflorescences appeared to be the main characteristic to be considered when searching for a higher seed production in white clover.
\end{abstract}

Key Words: flower bud, forage species, rip seed head, weight of 100 seeds

\section{Introdução}

O trevo-branco é importante para pecuária nos campos da Região Sul do Brasil por ser uma das leguminosas de maior potencial de utilização (EMBRAPA, 2000). O Rio Grande do Sul possui base agrícola forte e tradição na produção de sementes. Parte dessa capacidade tem sido utilizada para leguminosas forrageiras, maximizando economicamente o sistema de produção (Melo \& Barros, 2005).

Para melhorar a produção de sementes, são necessários estudos preliminares para se conhecer os componentes e as variáveis que determinam seu rendimento (Montardo et al., 2003).
O estudo das correlações entre caracteres é aplicável em praticamente todos os campos de pesquisa. A correlação simples permite apenas avaliar a magnitude e o sentido da associação entre dois caracteres, mas não fornece as informações necessárias sobre os efeitos diretos e indiretos de um grupo de caracteres em relação a uma variáveldependente de maior importância. A análise de trilha permite o estudo dos efeitos de várias variáveis independentes sobre uma variável básica, cujas estimativas são obtidas por meio de equações de regressão em que as variáveis são primeiramente padronizadas (Cruz, 2001).

A metodologia da análise de trilha foi adaptada e tem sido muito utilizada para investigar as relações entre os componentes do rendimento de sementes em culturas 
produtoras de grãos (Zaffaroni et al., 1998; ArchanaThorat et al., 1999; Board et al., 1999; Dencic et al., 2000); e também em plantas forrageiras, avaliando os componentes do rendimento de sementes (Iannucci \& Martiniello, 1998; Lord \& Kelly, 1999), e os componentes da produção de matéria seca (Kephart et al., 1992).

Objetivou-se com este trabalho determinar por meio da análise de coeficiente de trilha quais variáveis estão envolvidas no rendimento de sementes de trevo-branco, suas inter-relações e importância relativa.

\section{Material e Métodos}

Os dados utilizados na análise de trilha foram coletados por Franke \& Nabinger (1991) conforme a metodologia descrita a seguir.

O experimento foi instalado na Estação Experimental Agronômica da UFRGS, localizada na Depressão Central do Rio Grande do Sul ( $30^{\circ} 06^{\circ}$ de latitude Sul, 51 ${ }^{\circ} 39^{\prime}$ de longitude Oeste e $46 \mathrm{~m}$ de altitude). O solo da unidade experimental pertence à Unidade de Mapeamento São Jerônimo, classificado como Argissolo Vermelho distrófico típico Pvd (Streck et al., 2008), foi corrigido com $1.500 \mathrm{~kg} / \mathrm{ha}$ de calcário dolomítico, $120 \mathrm{~kg}$ de $\mathrm{P}_{2} \mathrm{O}_{5}$ na forma de superfosfato simples e $80 \mathrm{~kg} /$ ha de $\mathrm{K}_{2} \mathrm{O}$ na forma de cloreto de potássio. A semeadura foi realizada a lanço numa densidade de $4 \mathrm{~kg}$ de sementes por hectare, previamente inoculadas e peletizadas com $\mathrm{CaCO}_{3}$. Para avaliação dos componentes do rendimento de sementes de trevo-branco, foram utilizadas as cultivares BR 1 Bagé, Guaíba S1 e Jacuí S2 durante uma estação de crescimento, por meio de oito amostragens semanais.

O delineamento experimental utilizado foi o de blocos casualizados, com os tratamentos arranjados em parcelas subdivididas em quatro repetições. As cultivares constituíram as parcelas principais e as datas de amostragem, as subparcelas. As parcelas foram determinadas por um retângulo de $0,125 \mathrm{~m}^{-2}(0,25 \mathrm{~m} \times 0,50 \mathrm{~m})$ colocado na área útil de cada unidade experimental, em local diferente da amostragem anterior. As parcelas mediram $2 \mathrm{~m} \times 7 \mathrm{~m}$ e a área útil, 4,7 m² $(0,9 \mathrm{~m} \times 5,2 \mathrm{~m})$.

O número de botões florais por área foi determinado por contagem semanal no retângulo. Os números de inflorescências abertas por área e das inflorescências maduras foram determinados pela contagem semanal em floração plena (abertas e não-fecundadas) na área de $0,125 \mathrm{~m}^{2}$.

Para determinação do número de legumes por inflorescência, efetuou-se, em cada amostragem semanal, sua contagem em todas inflorescências completamente fecundadas, maduras e intactas. O peso de 100 sementes foi calculado a partir de quatro repetições de 100 sementes de cada amostragem em balança analítica com precisão de $0,0001 \mathrm{~g}$. A determinação do rendimento de sementes por parcela foi por meio da colheita das inflorescências maduras.

A análise estatística dos dados envolveu a análise das correlações simples entre as variáveis estudadas, e a análise de trilha propriamente dita, utilizando-se o aplicativo computacional GENES (Cruz, 2001).

\section{Resultados e Discussão}

Algumas variáveis apresentaram correlações positivas e significativas com o rendimento de sementes em trevobranco, portanto influenciaram de algum modo a expressão dessa variável (Tabela 1).

A variável que mais se correlacionou com rendimento de sementes foi o número de inflorescências maduras. A alta associação encontrada entre esses componentes de certo modo já era esperada, pois, segundo Hollington et al. (1989), o componente mais importante para obtenção de um satisfatório rendimento de sementes em trevo-branco é o número de inflorescências maduras no momento da colheita.

Outras correlações de interesse mostraram-se significativas, por exemplo: botões florais $\times$ rendimento de sementes, cujo coeficiente mostrou-se negativo $(\mathrm{r}=-0,55)$. De acordo com Hollington et al. (1989), o número de inflorescências e o número de inflorescências maduras são os principais componentes do rendimento de sementes da espécie. Logo, se há um alto surgimento de botões florais, haveria mais inflorescências e, na sequência, maior número de inflorescências maduras. O estudo de correlações simples entre caracteres não permite tirar conclusões sobre o estudo da relação de causa / efeito, pois a correlação é apenas uma medida de associação (Vencovsky \& Barriga, 1992).

Tabela 1 - Correlações simples entre número de botões florais (BF), número de inflorescências abertas (NIA), número de inflorescências maduras (NIM), número de legumes/ inflorescência (NLI), peso de 100-sementes (PCS) e rendimento de sementes de trevo-branco (REND)

\begin{tabular}{lcccccc}
\hline & BF & NIA & NIM & NLI & PCS & REND \\
\hline BF & - & $0,16^{*}$ & $-0,39^{*}$ & $-0,17^{*}$ & 0,08 & $-0,55^{*}$ \\
NIA & & - & $-0,28^{*}$ & $0,20^{*}$ & $0,14^{*}$ & $-0,17^{*}$ \\
NIM & & & - & $0,32^{*}$ & $0,29^{*}$ & $0,91^{*}$ \\
NLI & & & & - & $0,17^{*}$ & $0,46^{*}$ \\
PCS & & & & & - & $0,20^{*}$ \\
REND & & & & & & - \\
\hline
\end{tabular}

* Significativo a $\mathrm{P}<0,05$ pelo teste $\mathrm{t}$. 
Se todas essas variáveis influenciaram o rendimento de sementes e algumas delas apresentaram fortes correlações entre si, pode-se inferir que há um sistema de interrelações entre essas características, e que determinada variável poderia interferir no rendimento de sementes por meio de outra característica correlacionada (Figura 1).

Pela decomposição do coeficiente de correlação linear em efeitos direto e indireto (Tabela 2), observou-se forte associação entre o número de inflorescências maduras e o rendimento de sementes, cujos coeficientes lineares e de efeito direto são semelhantes. De acordo com Vencovsky \& Barriga (1992), quando o coeficiente de correlação e o efeito direto forem iguais ou semelhantes, em magnitude e sinal, essa correlação direta explica a verdadeira associação entre as variáveis. Isso demonstra que, aparentemente, essa variável atua com maior independência em relação às demais. Desse modo, para elevar a produção de sementes,

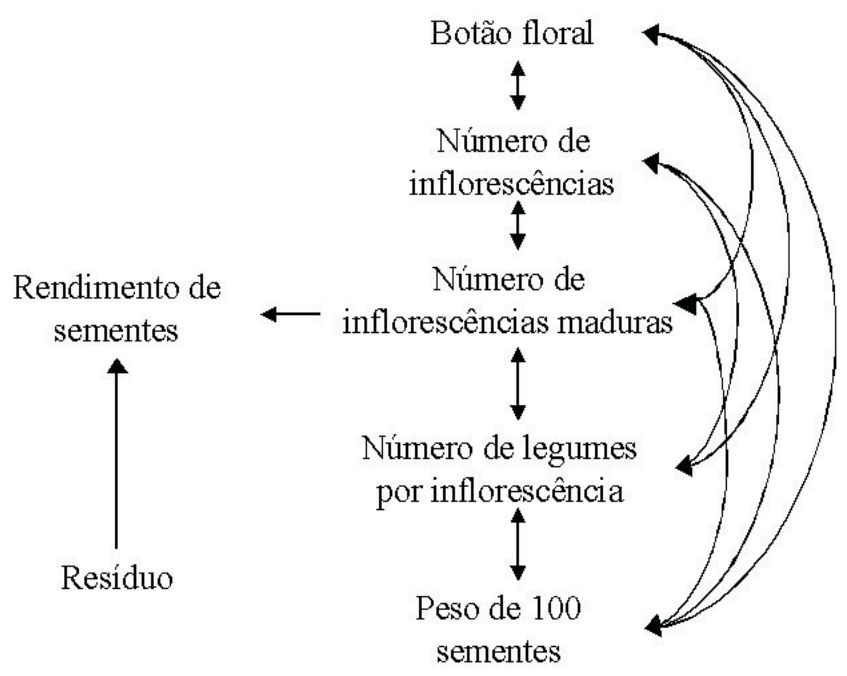

Figura 1 - Diagrama das variáveis consideradas na análise de trilha com suas inter-relações. deve-se otimizar a variável número de inflorescências maduras, cuidando, porém, para manter sob controle as demais variáveis. Caso contrário, poderia ter reflexos negativos no rendimento de sementes.

O segundo componente com maior coeficiente linear que influenciou o rendimento de sementes foi o número de botões florais (Figura 1). A decomposição do coeficiente linear dessa variável mostra um efeito indireto via número de inflorescências abertas quase desprezível (Tabela 2), ou seja, há pequeno grau de associação (positiva) entre essas duas variáveis.

No entanto, a influência da emissão de botões florais no número de inflorescências maduras e no número de legumes/ inflorescência e com menor intensidade no peso de 100 sementes foi negativa em relação ao rendimento de sementes. O comportamento negativo indica que, para aumentar o rendimento de sementes, é necessário diminuir esse componente, ou seja, maior número de botões florais tem efeito compensatório sobre o número de inflorescências maduras, o número de legumes por inflorescência e o peso de 100 sementes, em razão da competição por nutrientes na fase de diferenciação floral. Segundo Gibson \& Hollowell (1966), o trevo-branco apresenta desenvolvimento floral que se caracteriza por período longo de florescimento. As inflorescências emergem constantemente, de modo que podem existir em mesmo estolão inflorescências em diversos estádios de desenvolvimento, desde botões florais a inflorescências completamente maduras. Além disso, os componentes do rendimento normalmente estão negativamente relacionados, ou seja, o aumento de um pode resultar em decréscimo do outro (Almeida et al., 1998).

Quando a correlação linear é negativa e o efeito direto positivo, devem-se eliminar os efeitos indiretos da análise e aproveitar somente os diretos (Cruz, 2001), conforme se observa na decomposição do coeficiente da variável número de inflorescências abertas. Esses resultados contrariam os reportados por Jahufer \& Gawler (2000), que, avaliando os

Tabela 2 - Resultado da análise de trilha para rendimento de sementes em trevo-branco

\begin{tabular}{|c|c|c|c|c|c|}
\hline Item & $\mathrm{BF}$ & NIA & NIM & NLI & PCS \\
\hline Efeito direto sobre o rendimento & $-0,21$ & 0,07 & 0,80 & 0,16 & $-0,05$ \\
\hline Efeito indireto via BF & - & $-0,03$ & 0,08 & 0,04 & $-0,02$ \\
\hline Efeito indireto via NIA & 0,01 & - & $-0,02$ & 0,01 & 0,09 \\
\hline Efeito indireto via NIM & $-0,32$ & $-0,23$ & - & 0,26 & 0,24 \\
\hline Efeito indireto via NLI & 0,03 & 0,03 & 0,01 & - & 0,03 \\
\hline Efeito indireto via PCS & $-0,00$ & $-0,08$ & $-0,02$ & $-0,01$ & - \\
\hline Total $=\mathrm{r}$ & $-0,55$ & $-0,17$ & 0,91 & 0,46 & 0,20 \\
\hline Coeficiente de determinação & & & & & 0,90 \\
\hline Efeito da variável residual & & & & & 0,32 \\
\hline
\end{tabular}

$\mathrm{BF}$ = botão floral; NIA = número de inflorescências abertas; NIM = número de inflorescências maduras; NLI = número de legumes por inflorescência; PCS = peso de 100 sementes. 
componentes do rendimento de sementes em trevo-branco, relataram que a maior correlação foi observada entre o número de inflorescências e a produção de sementes. Quando os componentes do rendimento em trevo-branco foram avaliados com base na parcela (Annicchiarico, 1993), também o número de inflorescências por área figurou como a característica mais correlacionada à produção de sementes.

O número de legumes por inflorescência está diretamente correlacionado ao rendimento de sementes $(r=0,46)$ (Tabela 1). A correlação positiva entre essas duas variáveis ocorreu, indiretamente, pelo efeito dos botões florais $(r=0,04)$, pelo número de inflorescências abertas $(r=0,01)$ e, consequentemente, pelo número de inflorescências maduras $(r=0,26)$ (Tabela 2). O número de legumes por inflorescência depende do número de flores por inflorescência (não avaliado neste trabalho), assim como da condição dessas flores na época da polinização e fecundação e do número e eficiência dos insetos polinizadores.

O peso de 100 sementes apresentou coeficiente de correlação linear positivo em relação ao rendimento de sementes (Tabela 1). No entanto, seu coeficiente de efeito direto foi negativo (Tabela 2). Segundo Lorentz et al. (2006), quando o coeficiente de correlação linear for positivo, mas o efeito direto for negativo ou desprezível, a correlação será causada pelos efeitos indiretos, considerados na análise. A análise de trilha mostrou que essa correlação foi, em grande parte, explicada pelo seu efeito indireto via número de inflorescências maduras $(r=0,24)$.

A formação de numerosas inflorescências, inflorescências maduras e legumes por inflorescências gera sementes menores, tendo em vista a competição intrínseca de fotoassimilados pela planta na manutenção de sua sobrevivência. Segundo Carámbula (s.d.), os processos que controlam o peso das sementes são bastante complexos e controlados tanto por fatores externos, principalmente temperatura, nutrientes e umidade do solo e internos, quanto pelo vigor da planta (eficiência da fotossíntese e competição por nutrientes). Por outro lado, Annicchiarico (1993) encontrou alta correlação positiva $(r=0,89)$ entre peso de 1.000 sementes e produção de sementes em populações naturais de trevo-branco. Assim, essa característica, dependendo de sua variabilidade em determinada população, pode ser significativa na determinação do rendimento de sementes.

Neste trabalho, o alto coeficiente de determinação total $(r=0,90)$, associado ao efeito residual baixo $(0,32)$ (Tabela 2), indica que essas variáveis (componentes do rendimento) explicam os efeitos apresentados no diagrama causal (Figura 1) adotado para o rendimento de sementes em trevo-branco (variável básica).
Os resultados da análise de correlação e da análise de trilha foram muito semelhantes e apontam para o número de inflorescências maduras como a principal variável a influenciar o rendimento de sementes em trevo-branco. Apesar disso, a análise de trilha é importante, pois decompõe a análise de correlação em efeitos diretos e indiretos, o que imprime maior segurança no momento de se elegerem as características que deverão ser mais bem trabalhadas para se chegar ao objetivo final, no caso, o maior rendimento de sementes (Montardo et al., 2003).

Os mecanismos fisiológicos que ocorrem em trevobranco, por ser uma planta de hábito indeterminado e com período de florescimento longo, afetam o rendimento de sementes. Maior sucesso na produção de sementes e ressemeadura natural pode ser alcançado se forem concentrados esforços, tanto no melhoramento quanto no manejo, no período de florescimento, a fim de obter maior número de inflorescências maduras no momento da colheita.

\section{Conclusões}

O número de inflorescências maduras é a característica que mais se correlaciona com o rendimento de sementes. A emissão constante de botões florais influencia negativamente nos demais componentes do rendimento de sementes. A análise de trilha é um procedimento útil, preciso e de fácil aplicação no detalhamento das correlações entre as variáveis estudadas.

\section{Literatura Citada}

ALMEIDA, M.L.; MUNDSTOCK, C.M.; SANGOI, L. Conceito de ideotipo e seu uso no aumento do rendimento potencial de cereais. Ciência Rural, v.28, n.2, p.325-332, 1998.

ANNICCHIARICO, P. Variation for dry matter yield, seed yield and other agronomic traits in Ladino white clover landraces and natural populations. Euphytica, v.71, n.1-2, p.131-141, 1993.

ARCHANA-THORAT; NARKHEDE, M.N.; GITE, B.D. et al. Path coefficient analysis in soybean (Glycine max (L.) Merrill). Journal of Soils and Crops, v.9, n.2, p.250-251, 1999.

BOARD, J.E.; KANG, M.S.; HARVILLE, B.G. Path analysis of the yield formation process for late-planted soybean. Agronomy Journal, v.91, n.1, p.128-135, 1999.

CARÁMBULA, M. Producción de semillas de plantas forrajeras. Montevideo: Hemisferio Sur, [s.d.]. 518p.

CRUZ, C.D. Programa Genes: Versão Windows; aplicativo computacional em genética e estatística. Viçosa, MG: Universidade Federal de Viçosa, 2001.

DENCIC, S.; KASTORI, R.; KOBILJSKI, B. et al. Evaluation of grain yield and its components in wheat cultivars and landraces under near optimal and drought conditions. Euphytica, v.113, n.1, p.43-52, 2000

EMPRESA BRASILEIRA DE PESQUISA AGROPECUÁRIA EMBRAPA. Centro de Pesquisa de Pecuária dos Campos Sulbrasileiros. Melhoria da oferta forrageira para a Região Sul novas tecnologias. Bagé: 2000. 62p. (Documentos, 19) 
FRANKE, L.B.; NABINGER, C. Componentes do rendimento de sementes de cinco cultivares de trevo branco. Pesquisa Agropecuária Brasileira, v.26, n.9, p.1431-1445, 1991.

GIBSON, P.B.; HOLLOWELL, E.A. White clover. Washington, D.C.: USDA, 1966. 33p. (Agriculture handbook, 314).

HOLLINGTON, P.A.; MARSHALL, A.H.; HIDES, D.H. Effect of seed crop management on potential seed yield of contrasting white clover varieties. II. Seed yield components and potential seed yield. Grass Forage Science, v.44, n.2, p.189-193, 1989.

IANNUCCI, A.; MARTINIELLO, P. Analysis of seed yield components in four Mediterranean annual clovers. Field Crops Research, v.55, n.3, p.235-243, 1998.

JAHUFER, M.Z.Z.; GAWLER, F.I. Genotypic variation for seed yield components in white clover (Trifolium repens L.). Australian Journal of Agricultural Research, v.51, n.6, p.657-663, 2000.

KEPHART, K.D.; TWIDWELL, E.K.; BORTNEM, R. et al. Alfalfa yield components responses to seeding rate several years after establishment. Agronomy Journal, v.84, n.5, p.827-831, 1992.

LORD, J.M.; KELLY, D. Seed production in Festuca novae-zelandiae: the effect of altitude and pre-dispersal predation. New Zealand Journal of Botany, v.37, n.3, p.503-509, 1999.
LORENTZ, L.H.; FORTES, F.O.; LÚCIO, A.D. Análise de trilha entre as variáveis das análises de sementes de espécies florestais exóticas do Rio Grande do Sul. Revista Árvore, v.30, n.4, p.567-574, 2006.

MELO, P.T.B.S.; BARROS, C.S.A. Situação da produção de sementes de trevo branco (Trifolium repens L.), cornichão (Lotus corniculatus L.) e lotus anual (Lotus subbiflorus Lag.) no Rio Grande do Sul. Revista Brasileira de Agrociência, v.11, n.1, p.13-18, 2005.

MONTARDO, D.P.; DALL.AGNOL, M.; CRUSIUS, A.F. et al. Análise de trilha para rendimento de sementes em trevo vermelho (Trifolium pratense L.). Revista Brasileira de Zootecnia, v.32, n.5, p.1076-1082, 2003.

STRECK, E.V.; KÄMPF, N.; DALMOLIN, R.S.D. et al. Solos do Rio Grande do Sul. 2.ed. Porto Alegre: EMATER/RS, UFRGS, 2008. 222p.

VENCOVSKY, R.; BARRIGA, P. Genética biométrica no fitomelhoramento. Ribeirão Preto: Sociedade Brasileira de Genética, 1992. 496p.

ZAFFARONI, E.; TERRES, A.L.; BEVILAQUA, G.A.P. et al. Análise de caminho nos componentes do rendimento de genótipos de arroz no Rio Grande do Sul. Pesquisa Agropecuária Brasileira, v.33, n.1, p.43-48, 1998. 